\title{
Review of Impact of Climate Change on Ecosystem Services-A Review
}

\author{
Dubiso Gacheno*, Girma Amare \\ Haramaya University, College of Agriculture and Environmental Sciences, P.O. Box 138, Dire Dawa, Ethiopia.
}

\begin{abstract}
How to cite this paper: Dubiso Gacheno, Girma Amare. (2021) Review of Impact of Climate Change on Ecosystem Services-A Review. International Journal of Food Science and Agriculture, 5(3), 363-369.

DOI: 10.26855/ijfsa.2021.09.004
\end{abstract}

Received: June 5, 2021

Accepted: June 30, 2021

Published: July 15, 2021

*Corresponding author: Dubiso Gacheno, Haramaya University, College of Agriculture and Environmental Sciences, P.O. Box 138, Dire Dawa, Ethiopia.

Email: dubiso2136@gmail.com

\begin{abstract}
Ecosystem services (ES) are the direct and indirect contributions of ecosystems to human wellbeing, supporting survival and quality of life. Ecosystem services are benefits of natural ecosystems for human wellbeing. They can be classified into provisioning, regulating, supporting, and cultural services that are interacting in a complex dynamic. In the Arctic region, global change is affecting ecosystems' capacity to provide services in many ways: climatic warming is leading to alteration in ecosystems, natural resource exploitation is on the increase, and invasive alien species pose a threat to native biodiversity. The objective of this activity is to review impact of climate change on ecosystem services. Accordingly, different scholars' paper used to review the impact of climate change on ecosystem services. Ecosystem services can be affected by gradual changes in temperature or precipitation and climate-related disturbances like flooding, drought and wildfire, in association with other threats like land use change, pollution, overexploitation of resources. Majority of the projected impacts of climate change on ecosystem services are negative, so that to minimize impact of climate change on ecosystem services it is mandatory to practice climate smart agriculture by using technologies that support to mitigate and adapt climate change. In addition, it is also needed to use indigenous knowledge of land use managements like soil conservation, terracing and water shed managements; and also impact of climate change can be minimized with avoidance of deforestation, through schemes such as Reduced Emissions from Degradation and Deforestation which has co-benefits for the maintenance of forests dependent ecosystem services.
\end{abstract}

\section{Keywords}

Ecosystem Services, Climate Change

\section{Introduction}

\subsection{Background of the review}

Ecosystem services (ES) are the direct and indirect contributions of ecosystems to human wellbeing, supporting survival and quality of life. In the Arctic region, global change is affecting ecosystems' capacity to provide services in many ways: climatic warming is leading to alteration in ecosystems, natural resource exploitation is on the increase, and invasive alien species pose a threat to native biodiversity [1]. The global mean temperature is expected to rise by $1-5^{\circ} \mathrm{C}$ by the end of the twenty first century [2]. Climate warming is strongest in the northern latitudes including Northern Europe, Northern Russia [3], Greenland [4] and Northern Alaska and Canada. In addition, the Tibetan Plateau in Asia has been undergoing significant warming during recent decades [5]. The observed ecosystem responses to climate change around the Arctic include increasing shrub abundance, changes in precipitation and snow cover regimes, warming and thawing permafrost, drying lakes and wetlands, and increased fluxes of greenhouse gases, among others [6]. Climate warming and its interaction with many environmental, social, economic and political drivers strongly affects the way of 
life of the Arctic Indigenous peoples [7-10]. For Indigenous peoples, ecosystem services and cultural continuity are deeply intertwined and nature is the basis of everyday life [11].

Most ecosystems are vulnerable to climate change even under low- and medium-range scenarios of global warming [12]. They are likely to be affected by gradual changes in temperature or precipitation and climate-related disturbances (e.g., flooding, drought and wildfire), in association with other threats (e.g., land use change, pollution, overexploitation of resources). These changes and disturbances will affect ecosystem structure and function, the ecological interactions among species and their geographical ranges, which will result in changes in biodiversity and ecosystem services [13]. Ecosystem vulnerability has consequences for the global climate: if changes and disturbances release carbon into the atmosphere, vegetation-climate feedback will amplify global warming [14]. Local and regional ecosystem services may also be affected by climate change, such as water regulation or timber production, with direct implications for dependent societies [15].

Ecosystem services are benefits of natural ecosystems for human wellbeing. They can be classified into provisioning, regulating, supporting, and cultural services that are interacting in a complex dynamic [16].

1) Provisioning services refer to the products obtained from ecosystems such as food, fresh water, wood, fiber, genetic resources and medicines.

2) Regulating services are the benefits obtained from the regulation of ecosystem processes such as climate regulation, natural hazard regulation, water purification and waste management, pollination or pest control.

3) Supporting ecosystem processes and functions/habitat services include e.g. nutrient cycling, soil formation, photosynthesis as well as genetic, species and habitat diversity.

4) Cultural ecosystem services (CES) refer to non-material benefits that people obtain from ecosystems such as spiritual enrichment, intellectual development, recreation and aesthetic values [11].

These categories are interconnected, in particular in the Arctic where extreme environmental conditions make the coupling between physical processes (e.g. snow, ice, weather, geomorphology, wind), biological processes (e.g. species interactions and primary productivity) and human processes (e.g. land use) very tight and visible [11]. Moreover, in the holistic world view of Arctic Indigenous peoples, material culture and non-material culture are not separated, and in Indigenous ontologies, there is no boundary between nature and culture either: the two are intertwined and culture is everywhere. In their review regarding the ES in European North (including Sápmi), [17] estimated that there will be a decrease in some of the culturally important species and, consequently, in cultural ties to the land in the future. Otherwise, cultural and spiritual meanings of ecosystems, species and landscapes are rarely included in scientific research regarding ES. This may be the case because cultural and spiritual values provided by ecosystems are difficult to assess [18]. It has been noted that, in decision making in the Arctic and elsewhere, social and cultural attributes of ES are often given less emphasis than the economic benefits provided by ecosystems [11]. Thus, more studies regarding the status of CES in the Arctic region are needed. Also, more attention should be paid to those provisioning ecosystem services which are important for continuity of Indigenous people's cultures, as climate change will affect the very foundations of their nature-based way of life. When dealing with nature-based cultures, the overlap between cultural and provisioning ecosystem services is evident. Provisioning ecosystem services are also cultural services, and often a prerequisite for a meaningful life. For the Saami herders, for example, the quality of life and the persuasion that being a reindeer herder forms the meaning of their life can be more important than economic income provided by the livelihood [19]. Use of cultural and provisioning services, on the other hand, has an influence on some of the regulating and supporting services, e.g. reindeer grazing potentially affecting the climate through the albedo effect, and most certainly having an effect on the species biodiversity of the pastures.

With an increasing world population, the demand for provisioning services is increasing; at the same time, provisioning as well as regulating ecosystem services might be negatively affected by progressing climate change [20].

These events could affect ecosystem services such as water regulation and food [21]. Variation in water quantity such as an increase in winter discharge due to higher snowmelt and precipitation, reduction in summer discharge because of a reduction in the snow storage in winter, and increase in evapotranspiration could be expected [22]. Climate change is also altering biophysical production conditions, leading both to increase risks and emerging potentials for agricultural production. Furthermore, increasing frequency of extreme events and annual climatic variability may also lead to additional crop yield losses and reduce food provisioning services. In response to these changes, farmers will need to adapt their management in order to maintain or even increase production to satisfy the demands of a growing world population. Autonomous adaptation measures implemented by individuals or groups of farmers may aggravate conflicts between provisioning services and regulating/maintenance services or induce resource-use conflicts (e.g. for water and land). For example, an increase in irrigation to stabilize production under climate change may induce conflicts of water use or even lead to the overexploitation of water resources. To prevent such maladaptive responses, it is necessary to take an integrated perspective on climate change impacts, anticipating not only impacts on provisioning services, but also on regulating and supporting services, which are essential prerequisites for sustainable farming systems. A better understanding of joined responses of ecosystem services to climate and management drivers is helpful to support adap- 
tation planning and avoid maladaptive developments [23-24].

There have been many recent reviews of the effects of climate change on particular ecosystem services or classes of services, such as food, forests, or water.

\subsection{Objective}

$>$ To review impacts of climate change on ecosystem services.

\subsection{Ecosystem services}

\subsubsection{Provisioning services}

The absolute level of consumption of provisioning services globally is higher now than at any time in human history, due to growth in per capita demand and the size of the human population. Nevertheless, chronic shortfalls are apparent in many regions; and within regions, in sectors of society with limited access to services. The demand for provisioning services is projected to continue to grow during at least the first half of the 21st century, as the population rises from around 7 billion in 2010 to a projected 10 billion in 2050, at which point it may be nearly stabilized, for the first time since the Neolithic Revolution. This represents a $43 \%$ increase in population, but most authorities consider the increase in demand for provisioning services to be $70 \%-100 \%$ (i.e., up to a doubling of current demand), with the difference being due to increase in per capita resource use as people become generally better off.

The area expansion of agriculture (including biofuel crops and plantation forestry) and its increasing use of inputs such as water, nutrients, and pesticides, is a major driver of generally negative changes in other ecosystem services.

\subsubsection{Food Provision}

The effects of climate on the ecosystem service of 'food provision', and vice versa, have been the subject of many studies and reviews, so this section is longer than others. The briefest summary, for those not seeking details, is as follows: Climate change has spatially and temporally patchy effects on food provision, becoming generally negative for higher warming. Thus, for modest climate change $\left(1-2^{\circ} \mathrm{C}\right.$ rise in global mean temperature relative to preindustrial) global food provision is little affected, though food supply in many regions is already negatively affected, at $1^{\circ} \mathrm{C}$. Above $2^{\circ} \mathrm{C}$, the net effect becomes increasingly negative; and taking into account the rising demand for food and competition with other land and water uses (specifically, bioenergy production as a climate mitigation strategy), the risks to global and local food security from this level of climate change are high (the details follow). Food provision is ultimately about human food security (the availability of sufficient safe, nutritious food, to all, at all times, to paraphrase the World Food Summit of 1996) rather than food production alone. The key issues in food security often relate to affordability, access, and dietary preference rather than the capacity of the highly specialized food production ecosystems we call agriculture to deliver sufficient calories, proteins, and nutrients to meet the aggregate human need. Food, as a whole, is a non -substitutable good, but within that broad category there is great scope for substitution of one food type by another, with important ecosystem and cultural consequences. For instance, many studies conclude that a

'Western' diet (high in grain-fed animal protein and high-trophic level fish) cannot be extended to all the future global population without substantial expansion of the planted area and an unprecedented transformation in crop productivity and water use efficiency. The expansion of the area occupied by croplands ('extensification') and the increase in yield per unit area ('intensification' ) needed to ensure global food security if everyone consumed this aspirational diet would result in major losses of other ecosystem services, notably those which depend on uncultivated land and uncontaminated water. History demonstrates that when faced with a tradeoff between food security and other ecosystem services, the imperatives of hunger tend to override all other considerations. If, however, the diet is assumed to be nutritionally balanced and calorifically adequate but mostly based on vegetables, and food distribution is assumed to be efficient, several global studies conclude that food security is possible worldwide, even under modest levels of climate change (less than 2C GMT rise relative to the preindustrial mean, with the latter typically proxied by the 1850-1900 temperature) and with a global population reaching around 10 billion. This scenario would further require substantial reductions of waste in the food production system. It is not achievable without both expansion of agricultural area and intensification of agricultural management (i.e., increases in per unit land area inputs and outputs including unintended leakage of nutrients, salts, sediments, and pesticides).

\subsubsection{Crop agriculture}

Crop agriculture has been a major focus of climate impact studies. Broadly speaking, the studies find that despite the modest fertilization effect of rising CO2 (partly offset by simultaneously rising tropospheric ozone), locations of staple cereal and pulse production that are already hot during the growing season (i.e., daytime temperatures above the growth optimum for plants of $26-30^{\circ} \mathrm{C}$, and temperatures during the critical flowering and seed-set period exceeding $30^{\circ} \mathrm{C}$ ) experience yield declines under further warming, all else being equal. Places already dry notably the subtropical semi-arid zones are more likely to become drier than wetter in a warmer world, and are therefore likely to exhibit additional yield 
declines as a result. For those regions historically substantially cooler than the growth optimum for cereal yield and where moisture is currently comfortably adequate, yield increases are likely under a moderately warmer, wetter climate. Even at the relatively modest levels of warming experienced by 2015, local inability to meet food demand is apparent. It is very likely to increase in future, especially in the dry tropics. The risk of global food crises increases due to a combination of demand- and supply-side factors, some of which are directly linked to climate: such as greater inter annual climate variability (droughts and heat waves especially); the possibility of coincidental crop failures within the small number of global

'Bread baskets' which produce the bulk of staple crops worldwide; and the risk of damage to food sector infrastructure from severe storms. For global mean warming above $2^{\circ} \mathrm{C}$ relative to $1960-1990$, most global studies indicate a net decrease in food production, because yield declines become apparent in temperate as well as tropical areas. The amount of yield loss rises in an accelerating fashion with further warming, even when reasonable adaptive actions are taken. As the global scope for crop land expansion is now quite limited, the key adaptation to satisfy the projected doubling of food demand to mid-21st century is likely to be increased production per unit cultivated land and improved food system efficiencies, in both cases while trying to minimize the emissions of greenhouse gases from agriculture. The estimated rate of productivity increase required is at the upper limit of what has been possible in the past, around 2\% per year.

\subsubsection{Livestock and Dairy}

A large part of the global agricultural landscape is given over to the needs of domesticated livestock, including poultry and farmed fish, either directly as grazing lands, or for crops destined for animal consumption. As a result, of the quarter of global plant production that is appropriated for human use (Human Appropriation of Net Primary Production HANPP), a fifth to a quarter is consumed by domesticated species. The redirection of this fraction to direct human consumption is one of the strategies to make food security possible for a larger human population in the future. On the other hand, a large part of the grazing landscape devoted to animal production is located in places where the land is too dry, or the soils unsuitable, for crop agriculture. In these places, reducing animal production decreases, rather than increases human food security, and leads to livelihood losses. Dairy and meat production based on ruminant species generates about a quarter of global human related methane emissions. Emissions from enteric fermentation and animal wastes are mitigatable to a degree, but under current technology, not completely eliminated. As in the preindustrial era, rangelands usually supported large herds of wild ruminants, it is not a given that there has been a net increase of methane emissions following the replacement of wild ruminants by domesticated grazers. Although the impacts of climate change on animal feed production are similar to those outlined for crops above, animal-based production has a further temperature sensitivity: warm-blooded animals have a genetically inflexible body temperature, all within a narrow range. As the ambient temperature approaches the body temperature, animal productivity (and especially milk production) falls off steeply. The extensive rangelands of the world, where livelihoods and cultures are often closely linked to pastoralism, are often already quite close to this limit for all or part of the year, and many are projected to become both warmer and drier in future.

\subsubsection{Wild fisheries}

Overall, ocean primary production is projected to increase modestly under a +2C GMT increase, but the response of fish production is complicated by marine biome shifts, changes in body size, and the as-yet poorly understood effects of ocean acidification on fish production. Projections of ocean temperature changes suggest substantial geographical shifts in the locations of the broad types of marine fisheries during the 21st century as a result of climate change, but not necessarily a decrease in their total productivity (bearing in mind that the productivity of ocean fisheries is already under severe threat due to overfishing). Broadly, fisheries in tropical, temperate waters and Antarctic waters are projected to decline $40-60 \%$, while northern high latitude fisheries are projected to increase 30-70\%. Ocean acidification is an unavoidable consequence of rising CO2 levels with many direct and indirect impacts on wild-caught fisheries, predominantly negative. Recent reviews are available for this large, emerging field. Marine organisms which build their shells from calcium carbonate (in particular, the aragonite form of CaCO3) are severely negatively affected as the ocean $\mathrm{pH}$ falls toward and below 7.8 (a level which will be reached by end 21st century under 'business-as-usual' emission scenarios such as RCP 8.5). Affected organisms include wild-harvested and farmed molluscs and crustaceae, but also the many planktonic organisms on which the oceanic food web is based. Even marine organisms with an internal skeleton (such as fish) are susceptible.

\subsubsection{Regulating services}

Regulating services are the category believed to be most dependent on biological diversity and ecosystem integrity, and therefore most vulnerable to loss of diversity and the reorganization of communities as a result of climate change working in tandem with the many other causes of ecosystem disruption in the modern era.

\subsubsection{Helping to Stabilize the Climate}

The future behavior of the climate regulating service is particularly interesting in the context of climate change, be- 
cause of the potential for converting the currently dominant negative feedback loops (stabilizing) into positive feedback loops (destabilizing). If ecosystems are relied on for future assistance on moderating climate change, then the climate sensitivity of the mechanisms of carbon storage in ecosystems is of crucial importance. Currently, land and marine ecosystems are together absorbing about half of the anthropogenic $\mathrm{CO}_{2}$ emissions, helping to moderate the rate of climate change. In the oceans, the equivalent service comes with considerable risk to fisheries and biodiversity-related services, as a result of the accompanying ocean acidification. On land, the capacity to absorb $\mathrm{CO}_{2}$ is limited and time bound, because respiration or combustion of the stored carbon eventually balances or exceeds the uptake and the respiration rate increases with temperature, while the uptake rate saturates with rising $\mathrm{CO}_{2}$ and peaks and then declines with temperature. Furthermore, the incidence of wildfires has been observed to increase in some regions in recent decades and the fire risk is projected to increase under climate change. The fraction of anthropogenically emitted $\mathrm{CO}_{2}$ remaining in the atmosphere is rising and is projected to continue to do so. Thus, although the absolute magnitude of the oceanic carbon sink and the terrestrial carbon sink continues to increase, their proportional contribution to the carbon budget is declining at a global scale (this is what is meant by the '+' in REDD+). The climate regulating service of new afforestation is widely advocated as a mitigation activity. However, the net climate The avoidance of deforestation, through schemes such as Reduced Emissions from Degradation and Deforestation (REDD) has co-benefits for the maintenance of forests dependent ecosystem services change mitigation benefits of planting new forests in previously non forested environments is increasingly questioned, and the adverse tradeoffs in relation to other ecosystem services may limit this strategy. For instance, where such forest plantations result in a darker land surface, the climate benefits of carbon uptake are considerably offset or even nullified. This is unimportant in mostly cloudy locations, because it is the cloud cover rather than the land surface that controls the albedo. Thus, afforestation in the tropics is typically a net climate benefit, whereas in subtropical, temperate, and boreal areas it may not be. Where transpiration is increased as a result of afforestation, runoff is decreased. Plantation monocultures replacing previously species-rich vegetation represent a severe tradeoff between climate regulation and biodiversity protection.

\subsubsection{Protecting against Storm and Flood Damage}

Intact riparian and coastal vegetation have been widely shown to attenuate flooding and reduce bank and coast erosion. This service is generally in decline worldwide due to coastal and riparian development, but is projected to be increasingly important in a future of more extreme storms and sea level rise. Many of the initial set of Ecosystem-based Adaptation (EbA) projects are founded on the principle of enhancing this service.

\subsubsection{Keeping Pests and Diseases under Control}

Over the past centuries, there has been a proliferation in the extent, frequency, and severity of outbreaks of often novel diseases of humans, their plant and animal domesticates, and wild organisms, despite great advances in treatment technology. At the same time, there has been an increase in the spread of 'alien invasive species', that is, species that become very successful outside of their historical area of distribution. Many factors are involved in these changes: increased movement of people and goods, increased opportunity for trans-species disease transmission, larger and more densely packed human and livestock populations are among the explanations. In addition, there are plausible arguments that ecosystems are more vulnerable to the outbreak of single species populations, when they have reduced landscape and species diversity and are experiencing climate-induced stress. There is inferential evidence that scenarios of high climate change (which also typically represent futures where propagules move more easily by piggy-backing on trade and human movement) will be accompanied by further weakening of the ecosystem service of pest and disease suppression, which could then undermine the provision of other services. There are further potential negative impacts on the capacity to deliver pollination services (and the pest regulation services discussed above) resulting from changes in the structure (physical layout) and composition of the landscape, both of which are sensitive to climate change, among other drivers, especially if the change is rapid. Thus, the projections of the impact of climate change on the pollination service are generally pessimistic, though some commentators point to a high capacity for genetic adaptation in some pollinator species as a reason to be somewhat less pessimistic in the longer term.

\subsubsection{Cultural services}

The highly valued, but hard to quantify cultural services variously described as 'heritage', 'sense of place', 'identity', and 'spiritual' services are often based on patterns of landscape structure and composition, including the presence of particular species or features, which have co-developed with particular societies. Many of these will be climate-sensitive, but there is not an extensive formal ('scientific') literature dealing with climate risks to these cultural services. The possible vulnerability of these services is a concern more frequently raised by indigenous, traditional or local knowledge systems. Conversely, harnessing the power of cultural values has been invoked as an important strategy in adapting to climate change.

\subsubsection{Tourism and Recreation}

In contrast, the cultural services of recreation and tourism support a large market, and there is a correspondingly large 
formal literature. Some recreational services are highly vulnerable to global warming in their current locations: notably outdoor winter sports and possibly tropical holidays in places which could become dangerously warm, stormy, or more prone to disease. Those which are carbon-energy intensive (such as requiring travel to distant locations) are vulnerable to increases in the price of carbon-based energy. Cultural landscapes are under threat everywhere from many stressors, including climate change: not because their elements could not be recreated elsewhere, but because they may no longer be viable where the people who created them live.

\section{Summary and the Way Forward}

Ecosystem services (ES) are the direct and indirect contributions of ecosystems to human wellbeing, supporting survival and quality of life. They can be classified into provisioning, regulating, supporting, and cultural services that are interacting in a complex dynamic. These Ecosystem services can be affected by gradual changes in temperature or precipitation and climate-related disturbances (e.g., flooding, drought and wildfire), in association with other threats (e.g., land use change, pollution, overexploitation of resources). Ecosystem vulnerability has consequences for the global climate. If changes and disturbances release carbon into the atmosphere, vegetation climate feedback will amplify global warming. These changes and disturbances will affect ecosystem structure and function, the ecological interactions among species and their geographical ranges, which will result in changes in biodiversity and ecosystem services.

Generally, the majority of the projected impacts of climate change on ecosystem services are negative, so that to minimize the impact of climate change on ecosystem services it is better to practice climate smart agriculture by using technologies that support to mitigate and adapt to climate change. In addition to using technologies that support to mitigate and adapt climate change, it is also needed to use indigenous knowledge of land use managements like soil conservation, terracing and water shed managements.

\section{References}

[1] Kroglund, M., Lundeberg, T., Tennberg, M., Degtevea, A., Forsius, M., and Reiersen, L. O. (2017). Executive summary for the report on Adaptation Actions for a Changing Arctic: Perspectives from the Barents Area. In Adaptation Actions for a Changing Arctic: Perspectives from the Barents Area (pp. ix-xiv). Arctic monitoring and assessment programme.

[2] Stocker, T. F., Qin, D., Plattner, G. K., Alexander, L. V., Allen, S. K., Bindoff, N. L., ... and Xie, S. P. (2013). Technical summary. In Climate change 2013: The physical science basis. Contribution of Working Group I to the Fifth Assessment Report of the Intergovernmental Panel on Climate Change (pp. 33-115). Cambridge University Press.

[3] Sharmina, M., Anderson, K., and Bows-Larkin, A. (2013). Climate change regional review: Russia. Wiley Interdisciplinary Reviews: Climate Change, 4(5), 373-396.

[4] Abermann, J., Hansen, B., Lund, M., Wacker, S., Karami, M., and Cappelen, J. (2017). Hotspots and key periods of Greenland climate change during the past six decades. Ambio, 46(1), pp. 3-11.

[5] Kuang, X. and Jiao, J. J. (2016). Review on climate change on the Tibetan Plateau during the last half century. Journal of Geophysical Research: Atmospheres, 121(8), 3979-4007.

[6] Myers-Smith, I. H., Elmendorf, S. C., Beck, P. S., Wilmking, M., Hallinger, M., Blok, D., Tape, K. D., Rayback, S. A., Macias-Fauria, M., Forbes, B. C., and Speed, J. D. (2015). Climate sensitivity of shrub growth across the tundra biome. Nature Climate Change, 5(9), 887-891.

[7] Tyler, N. J. C., Turi, J. M., Sundset, M. A., Bull, K. S., Sara, M. N., Reinert, E., Oskal, N., Nellemann, C., McCarthy, J. J., Mathiesen, S. D., and Martello, M. L. (2007). Saami reindeer pastoralism under climate change: applying a generalized framework for vulnerability studies to a sub-arctic social-ecological system. Global Environmental Change, 17(2), 191-206.

[8] Stammler-Gossmann, A. (2010). 'Translating' vulnerability at the community level: Case study from the Russian North. In Community adaptation and vulnerability in Arctic regions (pp. 131-162). Springer, Dordrecht.

[9] Vuojala-Magga, T., Turunen, M., Ryyppo, T., and Tennberg, M. (2011). Resonance strategies of Sámi reindeer herders in northernmost Finland during climatically extreme years. Arctic, pp. 227-241.

[10] Jaakkola, Jouni J. K., Suvi Juntunen, and Klemetti Näkkäläjärvi. (2018). “The holistic effects of climate change on the culture, well-being, and health of the Saami, the only indigenous people in the European Union.” Current environmental health reports 5, no. 4 (2018): 401-417.

[11] Council, A. (2015). Conservation of Arctic Flora and Fauna (CAFF), “CAFF," available at arctic-council. org/working_group/caff.

[12] Scholes, R., Settele, J., UK, R. B., Bunn, S., Leadley, P., Nepstad, D., Overpeck, J., Biggs, D., Brando, P., Foden, W., and Goetz, S. (2014). Terrestrial and inland water systems. Ecosystems, 4, p. 1.

[13] Locatelli, B., Kanninen, M., Brockhaus, M., Colfer, C. P., Murdiyarso, D., and Santoso, H. (2008). Facing an uncertain future: How forests and people can adapt to climate change.

[14] Canadell, J. G., Ciais, P., Cox, P., and Heimann, M. (2004). Quantifying, understanding and managing the carbon cycle in the next decades. Climatic Change, 67(2), pp. 147-160. 
[15] Shaw, M. R., Pendleton, L., Cameron, D. R., Morris, B., Bachelet, D., Klausmeyer, K., MacKenzie, J., Conklin, D. R., Bratman, G. N., Lenihan, J., and Haunreiter, E. (2011). The impact of climate change on California's ecosystem services. Climatic Change, 109(1), 465-484.

[16] Millennium ecosystem assessment, M. E. A. (2005). Ecosystems and human well-being (Vol. 5). Washington, DC: Island Press.

[17] Jansson, R., Nilsson, C., Keskitalo, E. C. H., Vlasova, T., Sutinen, M. L., Moen, J., Chapin III, F. S., Bråthen, K. A., Cabeza, M., Callaghan, T. V., and van Oort, B. (2015). Future changes in the supply of goods and services from natural ecosystems: prospects for the European north. Ecology and Society, 20(3).

[18] Kettunen, M., Vihervaara, P., Kinnunen, S., D’Amato, D., Badura, T., Argimon, M., and Ten Brink, P. (2012). Socio-economic importance of ecosystem services in the Nordic Countries. Nordic Council of Ministers.

[19] Sköld, P. (2015). Perpetual adaption? Challanges for the Sami and reindeer husbandry in Sweden. In The New Arctic (pp. 39-55). Springer, Cham.

[20] Seidl, R. (2014). The shape of ecosystem management to come: anticipating risks and fostering resilience. BioScience, 64(12), 1159-1169.

[21] Schröter, D., Cramer, W., Leemans, R., Prentice, I. C., Araújo, M. B., Arnell, N. W., Bondeau, A., Bugmann, H., Carter, T. R., Gracia, C. A., and Anne, C. (2005). Ecosystem service supply and vulnerability to global change in Europe. Science, 310(5752), 1333-1337.

[22] Brunner, L., Lorenz, R., Zumwald, M., and Knutti, R. (2019). Quantifying uncertainty in European climate projections using combined performance-independence weighting. Environmental Research Letters, 14(12), 124010.

[23] Holzkämper, A. (2017). Adapting agricultural production systems to climate change—what's the use of models? Agriculture, 7(10), 86.

[24] Reidsma, P., Wolf, J., Kanellopoulos, A., Schaap, B. F., Mandryk, M., Verhagen, J., and van Ittersum, M. K. (2015). Climate change impact and adaptation research requires integrated assessment and farming systems analysis: A case study in the Netherlands. Environmental Research Letters, 10(4), 045004. 